\title{
Research progress and optimization prospect of constant boiling distillation technology
}

\author{
Heng $\mathrm{Ma}^{1, \mathrm{a}}$ \\ ${ }^{1}$ School of Chemical Engineering, Qingdao University of Science and Technology, Qingdao, China
}

\begin{abstract}
Coboiling distillation is a special distillation method of separating the azeotropic system mixture, which is widely used in petroleum refining and chemical production. This paper reviewed the selection and characteristics of azeoliling agents, and introduced the research progress of home and abroad in detail. The system compares the advantages and disadvantages of the traditional constant boiling distillation and the new heat pump, compare the advantages, and presents the prospect of constant boiling distillation.
\end{abstract}

\section{Introduction}

Coboiling distillation is the mass transfer and heat transfer to separate the coboiling system mixture, which is commonly used in the actual chemical production, widely used in petroleum refining and chemical product refining. When there are two cozeolite in the components or system with close relative volatility, it is difficult to separate the ordinary distillation method. For such systems, a large return ratio must be set by the conventional distillation method, which increases the equipment cost and operation cost in the actual production process and the economy is reduced.

Cozeoiling distillation is to add a third component with a low boiling point, called an azeoiling agent or binding agent, the new added component can form a low boiling point with one or two components of the original system, destroy the original boiling system, so that the dilemma separation component is effectively separated, the method becomes azeotropic (constant boiling) distillation ${ }^{[1-3]}$.

Cozeolite distillation is mainly suitable for the separation process of various organic compounds and hydrocarbon oxides. At present, there is more research on coboiling distillation technology in ${ }^{[4-6]}$, and the new heat pump and next tower technology are relatively reported. This paper summarizes the technical methods of traditional distillation process, new heat pump and heat pump, compares the advantages and disadvantages of the next process of new heat pump, obtains the advanced nature of the distillation, and provides theoretical reference and basis for the improvement ofindustrial production separation technology.

\section{Brief introduction of cozeoiling distillation}

\subsection{Selection of the azeotherite}

In the separation process of cozeolite distillation, the selection of azeolite agent plays a decisive role in the separation effect. The currently reported selection principles of coboiling agent ${ }^{[7-8]}$ mainly include:

(1) The selected azeozeolite should preferably be inhomogeneous to making the separation process simpler.

(2) Cozeolite can significantly affect the vaporliquid equilibrium relationship of the key components to be separated.

(3) The cozeolite forms with at least one or two components in the original system, destroying the cozeolite system in the original component. The newly formed azeolite should be more than $10{ }^{\circ} \mathrm{C}$ lower than the coboiling point of the coboiling ite with the original component.

(4) In the new formation of cozeolite, the lower the cozeolite content, can reduce the dosage and circulation.

(5) The azeolizer shall have small latent heat for vaporation to save energy consumption, and the azeolizer should have excellent chemical properties, with the characteristics of cheap price, rich raw materials, good thermal stability and small corrosion ability, non-toxic and environmental protection.

\subsection{Characteristics of azeoboiling distillation}

If ordinary distillation methods cannot meet the separation requirements, special distillation methods such as coboiling, extraction or variable pressure distillation can be used. Coboiling distillation has the following characteristics ${ }^{[9]}$ relative to other separation methods:

(1) The co-boiling distillation process is highly 
applicable and applicable for both continuous and intermittent operation.

(2) The boiling point of the azeotherite is high and must form a minimum azeolite with the components in the original component system and the selection range is limited.

(3)entrainer is often steamed from the top of the tower, large energy consumption, only the content of azeotropic agent is small in the new azeolite is more economical.

(4) The operating temperature of coboiling distillation at fixed pressure is relatively low and more suitable for separating thermosensitive materials.

\section{Progress in cozeoiling distillation}

\subsection{Progress of cozeolite distillation process}

\subsection{1 process of coboiling distillation}

$\mathrm{Yao}^{[10]}$ took the separation of $\mathrm{A}+\mathrm{B}$ mixture as an example and introduced the process of azeolboiling distillation. A is volatile component, low boiling point and light key component; B embarrassed volatile component, high boiling point and heavy key component.

In the process of coboiling distillation, the azeolite is soluble in component A and forms the lowest azeolite with A. Due to the low new coboiling point, the top material is heterogeneous mixture, and one phase contains more A and enters the component A recovery tower for further refining; the other is a mixture of azeolite and A (containing a small amount of A component), whose top backflow flows into the azeolboiling distillation tower. The specific flow chart of the coboiling distillation process is shown in Figure 1.

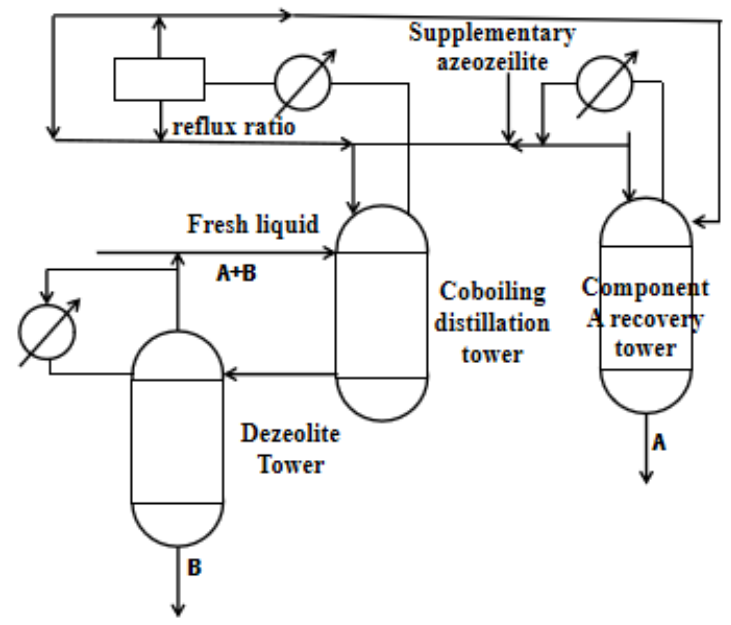

Figure 1 Distillation process with a two-component inhomogeneous azeotherite

From the above process flow chart, the fresh liquid mixture A and B enters the coboiling distillation tower, the top extracts the coboiling agent and the mixture of component $\mathrm{A}$ as reflux, the other part enters the component A recycling tower, which can finally be recovered at the bottom of the tower component $\mathrm{A}$. The material of the coboiling distillation tower enters the dezeolizer tower, where the top part of the B, tower returns, and the other part is mixed with the fresh material liquid and added into the azeolize distillation tower. In order to maintain the concentration of the feed or reflux, the process is the distillation process of heterogeneous cozeolite. In the case of ternary azeolite, the azeolizing agent can be added with fresh material liquid, cycle the ternary component azeolite at the top of the demazeolite agent tower, the pure B component distilled at the bottom of the tower, the upper layer of azeolite reflux at the top of the main tower, and the lower phase rich in component $\mathrm{A}$ enters the component A recovery tower for refining.

\subsubsection{Optimization direction of constant boiling distillation}

The biggest defect of the separation process is the large energy consumption. Many new energy-saving processes have been developed to efficiently and fully utilize energy and save ${ }^{[11]}$. It includes thermal integration technology, is a kind of heat logistics heat to heat cold logistics, reduce utility heating as far as possible, achieve heat integration and full utilization; in addition, thermal coupling technology, by improving the internal structure of the distillation tower, form a more complex tower structure, reduce the operation cost and equipment investment cost. Common energy-saving processes mainly include heat pump distillation, multi-effect distillation and adjacent tower distillation. In addition, middle condensation, intermediate reboiling and side extraction are also an energy-saving process through the middle condensate is the middle heat exchange, change the operation line of the distillation section, evenly distribute the heat transfer driving force in the tower, reduce the irreversible degree of heat transfer process, keep the fluid in steady flow state, and improve the separation efficiency.

\subsection{Constant boiling distillation process}

\subsubsection{Traditional constant-boiling distillation process}

Zhu Liuliu ${ }^{[12]}$ et al. produced $99.5 \%$ hydrless alcohol as an example, introduced the process of traditional constant boiling distillation process, Figure 2 is a process flow chart of production purity of $99.5 \%$ hydrless alcohol from conventional constant boiling distillation.

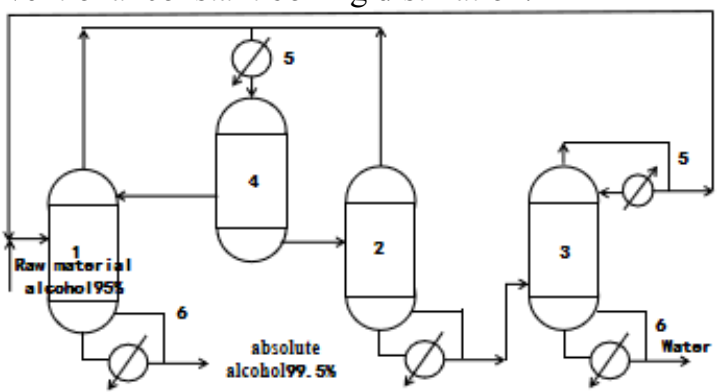

Figure 2 Traditional constant boiling distillation process raw material alcohol

Because it is more difficult to produce anhydrous alcohol under normal pressure conditions, the traditional constant boiling distillation process adds the azeolite that can form the lowest azeolite with ethanol (such as pentane, 
benzene), the azeolite can form ternary azeolite with water and ethanol, and the boiling point of the original solution, to produce high purity alcohol through $95 \%$ of the raw material alcohol.

The traditional constant boiling distillation method produces anhydrous alcohol after long development and improvement. The process has been mature and is widely used in anhydrous alcohol production enterprises. Its advantages lie in high product quality, large production, relatively stable production and relatively low operating cost, but its energy consumption compared with other advanced processes is the biggest problem, in addition, the azeoiling agent is high and may cause environmental pollution problems in the actual production.

\subsubsection{New process of Alcohol by constant boiling distillation of heat pump}

As a new energy-saving process, heat pump distillation is to pressure the steam on the top of the tower heat up operation, recycle the tower top steam condensation latent heat, this part of the heat as the heat source of the tower kettle reboiler, so as to reduce the tower bottom reboiler, to achieve the effect of energy saving and consumption reduction. Heat pump distillation has achieved good energy saving and consumption reduction effect in the separation of alkane and alcohol components. It has been studied to combine the heat pump technology with constant boiling distillation. This process is not only applicable to the difficult separation system, but also has a good energy saving effect. In the actual production, the system operates in the fully closed system, producing no harmful by-products, which is relatively environmental friendly.

Considering the small temperature difference of the dehydration tower under constant pressure $\left(10-15^{\circ} \mathrm{C}\right)$ Conditions for heat pump distillation. Liu Zongkuan et al. developed a new azeotropic distillation heat pump to pro duce anhydrous ethanol ${ }^{[13]}$. The ternary azeotrope on the top of the dehydrating tower $\left(64.6{ }^{\circ} \mathrm{C}\right)$ is heated to about $100^{\circ} \mathrm{C}$ directly through the heat pump, without the conde nsation process of the condenser. The energy produced $b$ $y$ this process can be used as heat at the bottom of the de hydrating tower, eliminating a reboiler. After the separati on of the condensate, the upper benzene-

rich phase is used as the top reflux, and the lower waterrich phase flows into the entrainer recovery column. The ethanol and water mixture at the bottom of the recovery $\mathrm{c}$ olumn flows into the alcohol recovery column for further refining. The cozeolite distilled at the top of the alcohol recovery tower does not undergo the condensation process at $78{ }^{\circ} \mathrm{C}$, and is pressurized to the heat pump to $120{ }^{\circ} \mathrm{C}$ to provide heat to the alcohol recovery tower, once again saving a rezeiler and saving energy consumption. The list of process parameters of anhydrous ethanol developed by Liu Zongkuan et al. ${ }^{[13]}$ is as follows:
Table 1.Process parameters of anhydrous ethanol produced by constant boiling distillation heat pump

\begin{tabular}{|c|c|}
\hline name & numerical value \\
\hline $\begin{array}{c}\text { Temperature difference between } \\
\text { tower top and tower kettle }\end{array}$ & $13^{\circ} \mathrm{C}$ \\
\hline $\begin{array}{c}\text { Alcohol dehydration tower tower } \\
\text { top steam temperature }\end{array}$ & $64.6^{\circ} \mathrm{C}$ \\
\hline Heat pump compressor heat up 1 & $100^{\circ} \mathrm{C}$ \\
\hline $\begin{array}{c}\text { Alcohol recovery tower top } \\
\text { vapor temperature }\end{array}$ & $78^{\circ} \mathrm{C}$ \\
\hline $\begin{array}{c}\text { Heat pump compressor heat up } 2 \\
\text { Alcohol recovery tower and } \\
\text { kettle temperature }\end{array}$ & $120^{\circ} \mathrm{C}$ \\
\hline
\end{tabular}

Heat pump constant boiling distillation has many advantages. First of all, to meet the requirements of technical and economic indicators, the product anhydrous ethanol is not vaporized, the distillation tower does not need a large return ratio, reduce operating costs and equipment costs. In addition, through the combination of heat pump technology and constant boiling distillation, the tower top materials are not condensing, and the heat pump compressor can be used as the heat source of the tower kettle reboiler, reducing the use of the reboiler and meeting the requirements of energy saving and consumption reduction. Through this process product high yield and no toxic substances during operation, is a clean production process.

\subsubsection{Technology of co-boiling distillation of heat pump}

Next door tower distillation ${ }^{[14]}$ is a higher separation requirements by improving the internal structure of the tower, and can also be combined with a heat pump to further reduce energy consumption. The next tower is divided into four parts, the feed first enters the preseparation section, the $\mathrm{A}-\mathrm{B}, \mathrm{B}-\mathrm{C}$ component mixture is separated in advance, the light component $\mathrm{A}-\mathrm{B}$ enters the distillation section, the heavier B-C enters the distillation section, the lighter A component of the distillation tower is extracted from the top of the tower, the heavy $\mathrm{C}$ component is extracted from the tower kettle, the $\mathrm{B}$ component enters is the lateral extraction section, and the material is the more pure B component. Steam in the tower flows upward, the liquid phase flows downward, the gas and liquid of each tower plate are in the phase balance process, the operation is relatively stable, and the quality transfer heat transfer effect is good.

The process of the next tower of the heat pump is the intermediate heat exchange, which can achieve efficient separation of the ternary complex system, and expand the heat pump technology to the wide boiling series separation ${ }^{[15]}$. Constant boiling distillation of the adjacent tower is a typical example of heat-coupled distillation, improving the structure of the two distillation towers into one distillation tower.

Chen Mengqi ${ }^{[16]}$ et al. have developed a new process 
of co-boiling distillation of the next tower. The steam on the top of the main tower is compressed as the heat pump compressor heat source at the bottom of the tower, and conducts heat exchange with the tower kettle logistics. The feed and organic phase obtained from the phase divider enter the top of the main tower, the tower top pressure is set to $101.35 \mathrm{KPa}$, the partition door top material enters the coboiler recovery tower, and the pressure is also set to $101.35 \mathrm{KPa}$. The heat load of the tower in the coboiler recovery tower is $1208 \mathrm{KW}$, temperature is $102{ }^{\circ} \mathrm{C}$, and the final EDA purity reaches 99.7\%. This process has high yield, high purity and energy saving, providing new ideas for the improvement of coboiling distillation process and useful reference for the next tower technology of heat pump and the combination of coboiling distillation process. The process parameters of heat pump co-boiling distillation next tower developed by Chen Mengqi ${ }^{[16]}$ et al. are as follows:

Table 2.Process parameter value of adjacent tower with coboiling distillation of heat pump

\begin{tabular}{|c|c|}
\hline name & numerical value \\
\hline Number of main tower(MC) & 71 boards \\
\hline Main tower top pressure & $1.013 \mathrm{bar}$ \\
\hline $\begin{array}{c}\text { Top pressure of the partition } \\
\text { door }\end{array}$ & $1.013 \mathrm{bar}$ \\
\hline $\begin{array}{c}\text { Heat load of coboiler } \\
\text { recovery tower kettle reboiler }\end{array}$ & $1207.6 \mathrm{~kW}$ \\
\hline $\begin{array}{c}\text { Temperature of cozeolite } \\
\text { recovery tower kettle }\end{array}$ & $103^{\circ} \mathrm{C}$ \\
\hline $\begin{array}{c}\text { Pressure of azeotropic agent } \\
\text { recovery tower kettle }\end{array}$ & $1.063 \mathrm{bar}$ \\
\hline EDA Moore purity & $99.7 \%$ \\
\hline
\end{tabular}

\section{Conclusions}

Distillation is an important separation and purification method in the chemical field. For some difficult separation or azeoliling systems, it can be efficiently separated by destroying the lowest azeolite system, and is widely used in chemical product refining. At present, there has been a substantial theoretical foundation in fluid mechanics, process control and gas-liquid heat and mass transfer of distillation tower. Modern chemical industry has put forward higher requirements for separation requirements, and separation technologies such as coboiling distillation are also constantly optimized and improved. Firstly, the research status of constant boiling distillation and tower distillation of the heat pump introduced the three processes in detail. Secondly, the advantages and disadvantages of the three processes are analyzed, highlighting the advantages of constant boiling distillation next to the heat pump, which not only realizes high purity, high yield, greatly reduces energy consumption, makes full use of steam energy, and has good heat transfer quality transfer effect, which is an effective combination of the heat pump tower technology and constant boiling distillation. Finally, the development prospect of coboiling distillation process is looked forward and provides theoretical reference and design basis for the improvement of industrial production separation technology.

\section{References}

1. Liu Tong, Ye Qing, Chen Jingxing, Cen Hao. Simulation and Optimization of the Separation of Bioalcohol-Water Mix [J]. Petroleum Journal (Petroleum Processing), 2019,35 (05): 938-947.

2. Li Zhizhuo, Jiang Zhankun, Zhang Xianghe. Research and application progress of azeotropic distillation technology $[\mathrm{J}]$. Shandong Chemical Industry, 2015,44 (03): 37-39.

3. Hu Song, Zhang Bingyan, Yu Zhihong, et al. Application and Research of Cozeiling Distillation in Chemical Production [J]. Chemical progress, 2010,29 (12): 2207-2219.

4. Zhou Qiang, Wu Gang, Zhuang Lizhen. Application of cozeiling distillation in tetrachloroethylene dehydration [J]. Chloralkali, 2019 (09): 39-41.

5. Sun Guoxiu, Cui Xianbao. Study on the heterogeneous intermittent coboiling distillation process [D]. Tianjin: Tianjin University, 2007.

6. $\mathrm{Xu}$ Bin. Application and optimization of energysaving technology of constant boiling distillation [J]. Chemical Management, 2020 (09): 58-60.

7. Ren Helen, Andenchao, Zhu Taoyue, Li Hailong, Li Xingang, Rectification Technology Research Progress and Industrial Application [J]. Chemical Progress, 2016,35 (06): 1606-1626.

8. Lyu X Y, Zhao L, Wang W C, et al. Heat-pump azeotropic distillation for ternary azeotrope ethanoltoluene water separation [J]. Journal of Changzhou University, 2017, 29(6): 26-31.

9. Li Fangsheng, Wang Xuyun, Qi Yunguo. Study on butanone-water heterogeneous intermittent coboiling distillation [J]. Chemical Engineer, 2020,34 (05): 2529.

10. Yao cang. Simulation Study of Phase Balance and Separation Process of Sparse Acetic Acid ExtractionCoboiling Distillation System [D]. Yangzhou University, 2017.

11. Tian Peng. Process Design and Control of Ethonitrilen-propanol Cozeolite System [D]. Qingdao University of Science and Technology, 2016.

12. Zhu Liuliu. Simulation study on strengthening of distillation of fuel ethanol [D]. China University of Petroleum (East China), 2017.

13. Liu Zongkuan, Gu Zhaolin, He Yanling, Feng Xiao. Research on constant boiling distillation of fuel ethanol heat pump [J]. Chemical progress, 2003 (11): 1147-1149.

14. Xia Ming. Design and control of energy saving adjacent tower for separating cozeolite [D]. Tianjin University, 2014. 
15. Li Murong, Xu Liang, Xin Chun. Simulation of Wide BoSystem in Next Tower of Heat Pump distillation [J]. Chemical Journal, 2017,68 (5): 1906-1912.

16. Chen Mengqi. Control of conventional adjacent tower and heat pump [D]. China University of Petroleum (East China), 2018. 